\title{
Corrigendum to "Feeding vitamin E may reverse sarcoplasmic reticulum membrane instability caused by feeding wet distillers grains plus solubles to cattle" (Prof. Anim. Sci. 33:12-23)
}

\section{D. Chao, K. I. Domenech-Pérez, and C. R. Calkins}

The description of diets (Table 1, see next page) provided in this manuscript was incorrect. All references to $30 \%$ wet distillers grains plus solubles (WDGS) in this manuscript should actually have been 40\% WDGS. The first 2 lines of Table 1 have been corrected and are presented with the rest of the table.

The authors regret the error.

\section{LITERATURE CITED}

Chao, M. D., K. I. Domenech-Pérez, and C. R. Calkins. 2017. Feeding vitamin E may reverse sarcoplasmic reticulum membrane instability caused by feeding wet distillers grains plus solubles to cattle. Prof. Anim. Sci. 33:12-23. https://doi.org/10.15232/pas.2016-01569. 


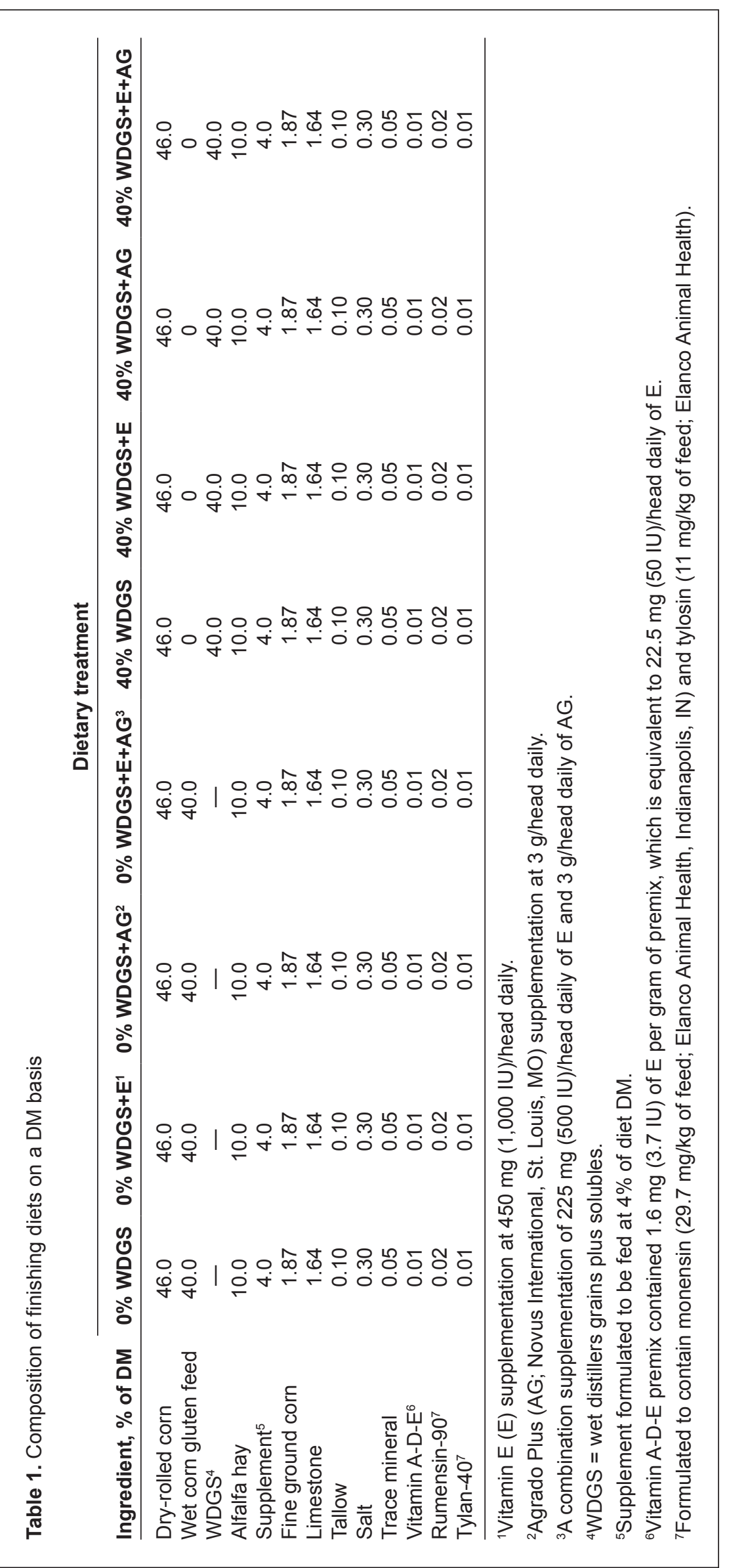

